\title{
6
}

\section{IMIGRAÇÃO E IMAGINAÇÃO: O BRASIL NA OBRA DE NEIRA VILAS}

\section{IMMIGRATION AND IMAGINATION: BRAZIL IN NEIRA VILAS' BOOKS}

\author{
Thayane Gaspar Jorge ${ }^{1}$ \\ Universidade Federal do Rio de Janeiro
}

Resumo: A forte presença de galegos fora do território da Galícia faz com que o fenômeno da imigração e suas implicações políticas, sociais e culturais ainda sejam assuntos frequentemente revisitados nos estudos galegos. Muitos desses estudos sobre emigração observam estereótipos galegos através de dados estatísticos, da literatura e de periódicos. Contudo pouco esforço foi conferido ao caminho contrário: qual é a presença do Brasil na literatura galega? Na obra de Xosé Neira Vilas pode-se observar algumas dessas representações sociais do Brasil, mais concretamente da cidade de Salvador de Bahia, pelos olhos imigrantes. Este artigo propõe o diálogo entre as atuais autoridades no assunto da diáspora e imigração galega como Ramón Villares, Antón Corbacho Quintela e Érica Sarmiento conjugados ao lado de teóricos das representações sociais e da análise do discurso como Denise Jodelet e Teun van Dijk.

Palavras-chave: Imigração; Galícia; Brasil; Literatura; Representações; Imagens.

1 thayanegasparj@gmail.com 


\begin{abstract}
The strong presence of Galicians outside the territory of Galicia makes the phenomenon of immigration and its political, social and cultural implications matters are frequently revisited in Galician studies. Many of these immigration studies observe Galician stereotypes through statistical data, literature and periodicals. However, little effort was given to the opposite path: what is Brazil's presence in Galician literature? In Xosé Neira Vilas' work, we can observe some of these social representations of Brazil through immigrant eyes, mainly on the city of Salvador da Bahia. This article proposes a dialogue between current authorities on the subject of diaspora and Galician immigration such as Ramón Villares, Antón Corbacho Quintela and Érica Sarmiento and theoreticians of social representations and discourse analysis like Denise Jodelet and Teun van Dijk.
\end{abstract}

Keywords: Immigration; Galicia; Brazil; Literature; Representations; Images.

\title{
$1 \quad$ OS GALEGOS NO BRASIL
}

Xosé Neira Vilas é uma grande voz da literatura institucionalizada e um dos grandes contribuidores para a consolidação da literatura infantil e juvenil galega, e boa parte da sua atuação aconteceu enquanto o autor vivenciava pessoalmente o fenômeno da emigração. Neira Vilas demonstrou ao longo de toda a sua vida e trajetória literária um grande compromisso com a língua além de suas fronteiras. Como um dos resultados da sua passagem pela América, acabou por unir a história de galegos e brasileiros na obra Cartas a Lelo (1971), livro que forma parte de uma trilogia iniciada pela obra-prima Memorias dun neno labrego (1961) e rematada com Aqueles anos do Moncho (1977). Essas três histórias se entrecruzam por compartilharem o mesmo núcleo de personagens: Balbino, Lelo e Toño. Os três meninos são produtos do mesmo contexto social, uma pacata aldeia galega, e assumem a posição de interlocutores e representantes de galegos que foram impelidos a emigrar e aqueles para os quais a emigração não era nem uma opção viável.

Memorias dun neno labrego (1961) foi publicado no Editorial Follas Novas em Buenos Aires, editora criada pelo próprio autor e sua esposa, Anisia Miranda. Esta obra inaugurou os tópicos centrais a partir dos quais a obra narrativa de Neira Vilas vai se sustentar: a infância, a aldeia natal e a emigração: 
En 1971 o autor de Gres publicou en Edicións do Castro Cartas a Lelo, incluída na colección "narrativas pra nenos" e ilustrada tamén por Luís Seone. Balbino funciona aqui como elo entre dous rapaces amigos seus: o personaxe principal da historia, Lelo, un mozo emigrado a Brasil e destinatario das vinte e unha cartas de Toño de Loureiro, o Peilao, quen segue a vivir na aldea natal dos tres rapaces. Este xogo metaliterario esténdese tamén á trama narrativa, na que se volve a reflectir a pobreza, os sufrimentos e miserias na vida cotidiá, as ánsias de liberdade e mellora e as vivencias comúns dos personaxes. (ROIG-RECHOU, 2015, p. 88)

Estas três obras foram compiladas pelo editorial Akal num volume intitulado O ciclo do neno (1978) enfatizando ainda mais a ideia de continuidade e complementariedade entre os textos de Neira Vilas. A trilogia é considerada a fundadora da Literatura Xuvenil galega principalmente pela presença de paratextos e uma clara intenção de público-alvo.

Nas obras são trazidas à tona reflexões sobre modelos culturais e identitários galegos que se contrastam, principalmente em Cartas a Lelo, com a curiosidade sobre os novos mundos para os quais os galegos são empurrados pela emigração a partir da tomada de consciência das diferenças identitárias dessas novas realidades. A terra natal, o deslocamento e a emigração são experiências costuradas através do conceito chave de memória e todo o processo discursivo imagético e imaginativo da percepção de si e do outro quando os personagens abandonam o limitado simulacro do mundo rural galego:

Nas tres obras aparecen tipos de memorias: o diário persoal de Balbino, convertido en libro de memorias, na primeira entrega; a transcrición das cartas de Toño a Lelo, na segunda; e o relato en terceira persoa duns anos concretos da vida de Moncho, na derradeira. Así, Balbino, Lelo e Moncho, veciños e amigos na primeira entrega, oscilan entre protagonistas e personaxes nas seguintes. Os tres nenos parten do mesmo contexto social dunha aldeã pobre galega e, consonte medran, van descobrindo novas realidades sociais na emigración e noutras vidas galegas, movidos por un afán de superar as consecuencias derivadas da Guerra Civil española. (ROIG-RECHOU, 2015, p. 90) 
Entretanto, Neira Vilas não foi o primeiro autor a se ocupar e fazer menções ao Brasil. O Brasil manifestou-se no imaginário galego desde Rosalía de Castro, mãe da literatura galega moderna, quando ela escreveu estes versos em Cantares Gallegos² em 1863: "Se o mar tivesse varandas fora-te ver ao Brasill Mas o mar não tem varandas,/ meu amor, por donde hei d'ir?". Se Rosalía entendia o oceano Atlântico como ponte e não como fronteira, o mesmo fez Castelao $^{3}$ em Sempre en Galiza (1944) ao conceber a língua como a própria ponte em suas reflexões sobre as aproximações entre o galego e o português falado em Portugal e no Brasil.

Apesar de Rosalía e Castelao, a literatura galega contemporânea não conta com muitas referências à terra brasileira ainda que a discussão sobre a estreita relação entre Galícia e Brasil seja inquestionável na atualidade. Ainda assim, as poucas obras que compõem essa amostra deveriam cobrar mais importância e atenção nos estudos galego-brasileiros. Na contemporaneidade a terra verde amarela é palco em obras como Todo ben (1984) de Manuel Rivas, O nome da Morte (2007) de Vitor Vaqueiro e Nordeste (2016) de Daniel Asorey. Separadas por um lapso temporal, as obras literárias apresentam um denominador comum: o tema da emigração e as representações do Brasil desde um ponto de vista galego.

Segundo o político espanhol Rafael María de Labra “A Galiza não se compreende sem a América". Esta afirmação ilustra o grande fluxo de imigrantes galegos que cruzaram o Atlântico de forma mais intensa a partir de 1800. Dentre os principais destinos estava Argentina - conhecida como a quinta

\footnotetext{
2 Rosalía de Castro é uma das maiores escritoras galegas, reverenciada tanto na literatura galega quanto espanhola. Considerada a fundadora da literatura galega moderna graças à publicação do livro Cantares Gallegos em 17 de maio de 1863, obra escrita inteiramente na língua galega dando início à renascença literária galega após séculos de silenciamento de produção literária no idioma. Ao lado do dos escritores Eduardo Pondal e Curros Enríquez, ela protagoniza a tríade dos escritores mais importantes o movimento literário do século XIX chamado Rexurdimento.

${ }_{3}^{3}$ Alfonso Daniel Manuel Rodríguez Castelao (1886-1950) foi médico, escritor, político, artista e fundador do nacionalismo galego.
} 
província galega uma vez que recebeu metade do contingente galego -, seguida por países como Cuba, Uruguai, Brasil e Estados Unidos (VILLARES, 2015).

A intensa emigração de galegos nos séculos XIX e XX não foi um episódio pontual na história da Galícia. O círculo vicioso da migração se inicia no século XVI com a imigração sazonal entre Galícia, Castela e Portugal impulsionada pelas colheitas de cereais. É somente em 1800 esse movimento migratório extrapola a península Ibérica e se dirige ao continente americano. Até 1930 os galegos cruzaram o Atlântico por conta de fatores externos de caráter político, econômico e pessoal. Encontramos entre as motivações desde medidas de incentivo à mão de obra barata e até fatores internos como a promessa de aventura, o fracasso da implementação do capitalismo e a situação precária e opressora nos campos assolados pela prática do caciquismo ${ }^{4}$ e da usura.

Por conta desse panorama opressor, boa parte desses imigrantes eram provenientes do campo e se submetiam a subempregos urbanos. Os imigrantes galegos no Brasil aos quais nos referimos apresentavam um perfil pouco dinâmico composto por homens entre 18 e 50 anos cujas passagens eram financiadas através de vendas de propriedades, hipotecas de casas e até mesmo custeadas pelas pessoas responsáveis por empregá-los na América.

Esses homens, em sua maioria, retornavam a Galícia definitivamente ou provisoriamente. Partiam dos portos da Corunha, de Vigo e também de Portugal, o que dificulta uma precisão nos dados que dizem respeito à origem desses estrangeiros no Brasil. As mulheres começaram a emigrar na segunda metade do século XIX, o seu número era inferior ao dos homens, porém isso não quer dizer que a emigração não tenha sido um fator transformador na vida

\footnotetext{
${ }^{4}$ Esta estratégia política girava em torno de um líder político que possuía domínio sobre uma comunidade rural, impondo restrições e altíssimos impostos alinhados a objetivos do governo central, instituindo uma espécie de oligarquia, cujo líder era denominado "cacique".
} 
das mulheres galegas em geral. Este fenômeno abalou e alterou a dinâmica das funções tradicionalmente atribuídas a homens e mulheres na sociedade galega e criou estigmas contra os quais as mulheres que emigraram precisaram lutar (OROZA, 2011).

A emigração deu à sociedade galega frutos podres, mas também sementes. As críticas e os impactos foram diversos como a diminuição de falantes de galego na população que refletia uma postura de renúncia e de descomprometimento com a melhoria da terra, como acusavam os galeguistas da época. A estrutura social foi reconfigurada no seu quadro demográfico gerados pela baixa natalidade e o aumento de mulheres solteiras. Para além desse balanço negativo, também há de se pensar na emigração como um elemento propulsor da cultura, educação e economia.

Graças ao dinheiro da emigração que chegava aos bancos locais, muitos campesinos conseguiram se tornar proprietários de terra e por fim livraram-se dos encargos que os sufocavam. O capital líquido ajudou a controlar o déficit da balança espanhola e propiciar uma certa modernização em diferentes áreas da Galícia. O segmento cultural deve muito à emigração na América, onde foram publicadas obras canônicas da literatura galega e financiados diversos projetos educacionais que aumentaram o índice de alfabetização na Galícia.

De fato, a emigração afetou também a própria cultura e identidade dos galegos. A emigração inaugurou um grande tópico reproduzido ao longo dos séculos: o da morriña ${ }^{5}$, símbolo da nostalgia e do sentimentalismo que marca e demarca a definição do povo galego. A presença dos grandes intelectuais galegos neste momento fora das fronteiras demonstra que muito do que se entende por identidade e cultura galega foi, na verdade, pensada e formulada no exterior da Galícia. Essa construção exógena foi feita por escritores,

\footnotetext{
${ }^{5}$ Este estado anímico nostálgico e melancólico experienciado pela emigração.
} 
intelectuais e pensadores preocupados com a criação de uma identidade imaginada e, também, híbrida:

As suas manifestações são tão várias como historicamente complexas, mas todas elas confluem em presumir que o galego é um povo nostálgico, que vive em harmoniosa comunhão com a paisagem, ou, então, em pesarosas saudades, quando longe da terra. Essas imagens evocaram, de forma explícita e implícita, uma ligação milenar entre o povo galego, uma capacidade inata para a poesia e um caráter reservado, uma maneira de se estar no mundo desprovida de espírito prático e de realismo, mas também astuta e cautelosa. (MIGUÉLEZ-CARBALLEIRA, 2014, p. 14)

Para a proteção dos emigrantes, surgiram associações galegas preocupadas em providenciar ajudas nas áreas de saúde e na organização política e laboral, além de fomentar produções culturais e intercâmbio de informações através de revistas. As revistas, periódicos e literatura epistolar serviram a diversos propósitos e entre eles o de criar e fantasiar uma certa identidade galega, buscando perceber os costumes da terra natal e reproduzilos em terra estrangeira. Interessa-nos aqui saber o outro lado da moeda: como a nossa cultura foi exportada através desses documentos e discursos e qual identidade foi conferida e imaginada para o Brasil.

No contexto de produção do livro Cartas a Lelo, os emigrantes espanhóis já se constituíam como uma das três maiores colônias estrangeiras no Brasil ao lado das colônias portuguesa e da italiana. Dos dois milhões de espanhóis que vieram para o Brasil entre 1860 e 1970, 70\% seriam galegos (SARMIENTO, 2012) que se concentraram, sobretudo nas cidades de Salvador, Rio de Janeiro e São Paulo. A emigração no Brasil foi bastante diferente de outros países da América principalmente pela ausência da atividade galeguista e por uma certa forma de aculturação desses galegos:

Essa invisibilidade do imigrante galego não foi um fato universal que impeça de identificá-lo como tal. No entanto, assim como o imigrante português se metamorfoseou em terras brasileiras, fazendo daquele país, 
nas palavras de Lourenço Jorge, "um continente escrito em português, adoçado pela brisa dos trópicos", algo análogo sucede ao imigrante galego que, ou se assimila ao português minhoto ou forma parte do conjunto da imigração espanhola, como se pode claramente observar na maioria dos centros societários fundados nas capitais brasileira, de Santos, de São Paulo, do Rio de Janeiro ou de Salvador, onde a denominação étnica societária costuma ser espanhola, apesar da maioria de seus associados ser claramente de origem galega. Apesar desta invisibilidade, as marcas do imigrante galego em terras brasileiras são fortes ao ponto de a palavra "galego, ao contrário de outros lugares da América, se converter em gentílico que designa não necessariamente os imigrantes de procedência, mas sim os portugueses Assim percebeu com muita sagacidade o escritor político Castelao em suas anotações para a composição de Sempre en Galiza: "no Brasil chamam 'galegos' aos portugueses, e os galegos não querem ser confundidos com portugueses. Por isso preferem que os chamem de 'hespañoles', deixando o de "galego" aos portugueses." (VILLARES, 2015, p. 470)

No estado da Bahia, no século $X X$, os galegos eram o maior contingente estrangeiro vindos principalmente da província de Pontevedra. Segundo Jefferson Bacelar, os galegos não eram imigrantes desejados uma vez que poderiam provocar um desequilíbrio na situação de trabalho entre negros e brancos. Ainda assim, esses galegos viviam no antigo centro de Salvador e se dedicavam ao comércio de comidas e bebidas (BACELAR, 2013, p. 235).

Essa rivalidade gerou conflitos entre baianos e galegos, e esse atrito contribuiu para a consolidação e a reverberação de marcadores pejorativos, e até estigmatizados, pelos quais os galegos foram traduzidos na nossa cultura. Contudo, a presença galega na cidade de Salvador foi um elemento catalisador e importante para muitas transformações sociais e econômicas, além de ser um fator essencial para se entender e se perceber a construção identitária e histórica da cidade soteropolitana.

Entende-se, pois, que a cidade é um conjunto de espaços fragmentados com características próprias, balizados na prática socioespacial de cada segmento da sociedade que os ocupa. Isto permite considerar que a comunidade galega é um elemento cultural incorporado ao cotidiano soteropolitano e, assim como os demais, mantém relações e práticas sociais. 
Isto posto, torna-se pertinente afirmar que, a partir da perspectiva da Geografia Histórica, dá-se a existência de uma articulação voltada a moldar uma dimensão espacial do grupo, produzida na forma de territorialidade ou mesmo com o investimento em construção de objetos que, agregados à paisagem urbana, denotam a presença da galeguidade em Salvador.

Cartas a Lelo (1971) é um reflexo dessa importância e, também, da representatividade de imigrantes galegos no Estado da Bahia. Nessa obra ficcional de caráter epistolar, na qual o próprio autor se intitula "o carteiro", podemos observar as representações sociais do Brasil reverberadas entre Lelo e Toño.

\section{O BRASIL NA LITERATURA DE XOSÉ NEIRA VILAS}

A construção das representações sociais é um fenômeno complexo balizado por uma simbolização que marca profundamente a realidade psicológica, afetiva e social através de um discurso (JODELET, 2001). O pesquisador Antón Corbacho Quintela (2009) atribui como marco da representação do Brasil a partir da perspectiva galega o ensaio Brasil, la gran potencia del siglo XX, publicado em Santiago de Compostela em duas edições uma em 1955 e outra em 1957 pelo professor Antonio Mejide Pardo.

Este pioneiro artigo resume uma série de dados sobre a geografia, a economia e a demografia brasileira para chegar à conclusão de que o Brasil era um dos países mais promissores do século. Na mesma linha encontra-se o artigo El Brasil; riquezas, possibilidades (1946) publicado em espanhol pelo Ministério de Relações Internacionais do Brasil. Esta obra foi referenciada por Mejide e possuía um tom propagandístico elencando as vantagens econômicas para os que pensavam em investir de alguma forma na economia brasileira. 
Contudo, houve adventícios no Brasil dos quais não se esperava que se abrasileirassem; a função deles era a de conservarem a sua identidade, ora para mostrarem ao aborígine como era o outro que devia valer como referência pelo seu valor civilizacional, ora para, desde a sua alteridade, eles observarem o país que percorriam e a sua sociedade nativa, e, logo, comentarem, publicitariamente, a beleza do território e as virtudes das suas gentes. Os poucos escritores galegos, não-imigrantes, que vieram ao Brasil e, no Brasil, publicaram a narração com as impressões da sua experiência, estudados no capítulo quinto, encaixaram-se nesse modelo, contribuindo, portanto, à difusão de imagens ufanas no país e da capacidade deste para incorporar, desde a cordialidade, os imigrantes. Um paradigma extremo desse sujeito que assumia o projeto de fazer propaganda, por meio de uma publicação, das grandezas e das possibilidades de desenvolvimento de um país estrangeiro foi o do galego Antonio Meijide Pardo, cuja obra foi comentada no capítulo quinto. Ele, com o seu ensaio Brasil, la gran potencia del siglo XXI, e sem se ter deslocado ao Brasil, descreveu os ingentes recursos e a boa condução política do país que era o destino laboral que, contemporaneamente, escolhiam os seus compatriotas emigrantes para tentarem fazer fortuna. (QUINTELA, 2009, p. 889)

Igualmente limitadas são as obras literárias que nos permitem investigar as representações sociais feitas sobre o Brasil e sobre os brasileiros na Galícia. A lista, segundo Quintela, conta com Brasil, historia, xente e samba-canción de Xosé María García Rodríguez publicado em 1977 pelo Editorial Galaxia e com o romance de José Luis Casas, Sucedió en Brasil (1985). A primeira obra apresenta uma antologia de poemas em galego sobre personagens e acontecimentos históricos que esboçam algumas representações do Brasil, principalmente do Rio de Janeiro e do nordeste do país. O romance, por outro lado, tem como enfoque a história de um imigrante galego no Brasil, Álvaro, e suas sequentes frustrações em relação ao seu desejo de revolução.

Nessas quatro obras evidencia-se a posição do Brasil como um país de muitas promessas de prosperidade, aberto ao mundo e aos imigrantes, e ao mesmo tempo possuidor de uma política bastante clara sobre a construção nacional que implicava num certo "abrasileiramento" destes estrangeiros, que 
poderia ser interpretado, como sugere Antón Corbacho Quintela como uma aculturação.

Ao recopilarmos a produção cultural escrita dos imigrantes galegos nesses estados para ponderar em que grau se manifestara, nela, o galeguismo, percebemos que ela era muito escassa. Nesse sentido, observamos que, na sua maioria, os imigrantes galegos se comportaram estritamente como tais, isto é, como trabalhadores estrangeiros cuja presença no Brasil não se devera à demanda de realizações intelectuais, senão à execução de tarefas, próprias da mão-de-obra, na agropecuária, na indústria e nos serviços. Assim se tratando, a associação entre eles só aconteceu com fins empresariais, de socorros mútuos e de lazer, mas não culturais. As representações dos galegos feitas nos discursos de autores brasileiros, e de estrangeiros não-imigrantes, que comentamos mostram, predominantemente, sujeitos pacatos, de pouca cultura e sem inquietudes intelectuais, aferrados ao seu destino de imigrantes, ou seja, ao destino de sujeitos concentrados na sua missão de reunirem poupanças através da execução de qualquer tarefa relegada aos estrangeiros. (QUINTELA, 2009, p. 890)

Em Cartas a Lelo (1971), o Brasil é citado parcamente no texto, e é apresentado como uma combinação de oportunidade e exotismo. O Brasil não é o protagonista do texto e sim os três meninos Balbino, Toño e Lelo que simbolizam a situação de exploração e alienação das aldeias e que, ao mesmo tempo, representam os que vivem a emigração e os que sonham com ela.

Toño é quem escreve cartas a Lelo por intermédio de Balbino, quem lhe fornece o endereço da correspondência. As cartas de Lelo não são reproduzidas por Neira Vilas e temos uma comunicação por via de mão única, situação que nos convida a imaginar as respostas de Lelo, que emigrou à cidade brasileira de Salvador da Bahia com seus pais. Embora este seja um tema bastante corrente na literatura galega, Neira Vilas inova ao dar protagonismo não aos homens emigrantes que se destacam nos sensos dos dados históricos, nem às mulheres 
que emigravam ou as viúvas de vivo ${ }^{6}$ e sim às crianças que são atravessadas pelas situações proporcionadas pela emigração.

A primeira menção ao Brasil reflete uma celebração cultural bastante exportada ao exterior até os dias de hoje, o carnaval. No seu excerto correspondente sobressai a adjetivação empregada por Neira Vilas "pavera", "toleirón" equivalentes a "engraçada", "enlouquecido", "desvairado":

Pois é. O Balbino xa sabes que anda a servir dende que lle arreou cun pelouro ó Manolito. É un rapaz caviloso e de poucas falas. Hai algúns días veu á casa. Eu atopeino na beira do río e estivemos un anaco dando ó peteiro. Faloume de ti. Díxome que vos escribides e mostroume duas cartas túas, por certo moi paveras niso que dis do entroido toleirón do Brasil. (VILAS, 1971, p. 9)

Roberto Damatta, um dos mais emblemáticos antropólogos brasileiros, na sua conhecida obra O que faz brasil, Brasil? (2001, p. 25) já resume os tópicos comuns do que se entende por brasilidade e são eles o futebol, o carnaval, a riqueza natural do país, a miscigenação e a diversidade. Damatta define o carnaval como inversão, diversão, do excesso, da alma popular e da celebração da igualdade. Neira Vilas alude a esse exagero e a essa alegria como o abre alas da descrição do contato de Lelo com a cultura na terra do pau brasil.

O autor se refere, através das impressões de Lelo no Brasil, à tensão da ausência do mar na aldeia e a sua intensa presença na cidade de Salvador. O mar mais do que uma característica da paisagem da cidade baiana, transformase numa metáfora de comunicação, de oportunidade, de abertura para o mundo. Nesta menção ao Brasil, destacam-se gírias brasileiras, nomes de bairros e litorâneos e o mar:

\footnotetext{
6 Assim ficaram conhecidas as mulheres que perdiam contato com os maridos durante a emigração. Rosalía de Castro dedica uma seção do seu livro Follas Novas (1880) a essas histórias da migração.
} 
Bo é que xa vas contando algo. Polo que badúas, o Brasil é cousa grande. Vese que te afás nesa cidade do Salvador; que estás «feito un baiano», como dis. E que che gusta o mar. Aquí nada máis tiñas un río e agora fálasme de longos areeiros, ou praias, na beira dun mar sen cabo. Moi paveros eses nomes da Ribeira, Tañeiros, Peri-peri, Itacaraña... ¡Quen me dera ir e vir por lugares así! Eu nunca vin o mar. Ás veces falo del co Marxado; súa tía a máis vella vai todos os anos ós baños e cóntalle cousas. Pero mellor era velo, batuxar na auga como ti fas. Onde non, é coma soñar; ou coma ter unha moza por carta, digo eu. E xa que dixen moza, vouche contar da lea que tiven co Anselmo. (VILAS, 1971, p. 15)

Na passagem acima o único adjetivo utilizado para o Brasil e sua parte metonímica, o mar, é "grande", "sen cabo", que poderia fazer referência não só à sua dimensão territorial consideravelmente superior à da Galícia como também o futuro promissor do Brasil e à pequenez da terra galega.

Não se ausenta do discurso de Neira Vilas a ferida histórica carregada pelo Brasil por conta da escravidão que é traduzida na obra pela forte presença de negros na cidade soteropolitana e pelas reminiscências da cultura africana como a prática do jogo e da dança da capoeira:

Esta vez tardaches en escribir. Ou, cando menos, tardou en chegarme a túa carta. Por certo que a fun ler á casa do Marxado. E falamos dese xogo e desas danzas da capoeira. Os choutos e reviravoltas que fatos de homes negros andan a facer nas aforas do Salvador son cousa pavera. ¿Así que o costume veu da África? Cómpre ter ósos bulidores, afeitos dende hai moitos anos, para aturar tales xogos. Os campións de que falas, Bilba e Olampo, debe dar xenio velos no seu rebulir. E non ha de ser menos engaiolante a ringleira dos tocadores de berimbau. ¡Ese Brasil...!

Sobressai nesta referência novamente o adjetivo pavera ["engraçada"] e engaiolante ["fascinante"], corroborando o exotismo e distanciamento entre Toño e a cultura brasileira. Alan Caldas em Valentia e linhagem: uma história da capoeira (2018) apresenta uma análise sociológica das identidades afro-brasileiras por meio da prática da capoeira e os conceitos de "cultura da valentia" e "ética da valentia". Caldas expõe a simbologia herdada pela capoeira em relação à 
ancestralidade e à honra guerreira africana. Na obra galega, a adjetivação e a atenção se voltam a aspectos físicos como a agilidade do corpo e excentricidade do espetáculo público.

Lelo não permanece no Brasil por muito tempo apesar de suas cartas sugerirem um grande fascínio e gozo na sua vivência na terra verde e amarela. Toño recebe a notícia de que seu amigo se deslocará para Montevideo com os pais enquanto Toño percebe o Brasil e a América Latina como algo muito distante, palpável apenas no mundo dos sonhos.

\section{CONSIDERAÇÕES FINAIS}

Xosé Neiras Vilas deixou um grande legado à literatura galega por legitimar a literatura infantil e juvenil e por representar a galeguidade presente na América Latina. Cartas a Lelo (1971) é uma obra exemplar pela sua poeticidade, pelo seu poder de reconstrução social e histórica e sobretudo por trazer à tona os laços criados e cultivados pelos imigrantes galegos no Brasil através da memória e da história. O Brasil de Neira Vilas é um Brasil do diferente, do atraente, do fascinante, mas talvez não tão promissor para a colônia de imigrantes como os materiais publicados na Espanha o faziam parecer.

As representações do Brasil e de Salvador de Bahia tocam a visão comumente exportada ao exterior: da alegria, da harmonia racial e da beleza sem diferir de estereótipos e lugares comuns nos tópicos da cultura brasileira. As cartas de Toño transmitem a ideia da experiência com o exótico e, acima de tudo, com o novo em contraste com o "velho" das aldeias, as poucas inovações e transformações, das pessoas velhas que permanecem no mesmo lugar quando as novas emigram. 
Desta forma, textos como o de Xosé Neira Vilas contribuíram para as representações do Brasil, simbolizando este objetivo e reproduzindo interpretações que atravessaram e construíram o imaginário dos indivíduos que se identificavam, de alguma forma, com o processo migratório por serem os destinatários, como Lelo, ou os rementes, como Toño, de cartas, memórias e histórias entre as duas bandas do Atlântico.

\section{REFERÊNCIAS}

CALDAS, Alan. Valentia e linhagem: uma história da capoeira. Curitiba: Appris, 2018.

CASTELAO, Alfonso Daniel Manuel Rodríguez. Sempre en Galiza. Vigo: Galaxia, 2004.

DIJIK, Teun A. van. Discurso y contexto. Barcelona: Gedisa, 2013.

JODELET, Denise. Representações sociais: um domínio em expansão. In: JODELET, Denise. (Org.). As representações sociais. Rio de Janeiro: EdUERJ, 2001. p. 17- 44.

MIGUÉLEZ-CARBALLEIRA, Helena. Galiza, um povo sentimental?: género, política e cultura no imaginário nacional galego. Santiago de Compostela: Através, 2014.

QUINTELA, Antón Corbacho. A aculturação e os galegos no Brasil: o vazio galeguista. Tese de Doutorado em História apresentada à Faculdade de Filologia Galega da Universidade de Santiago de Compostela. Santiago de Compostela, 2009.

RIVAS, Manuel. Todo ben. Vigo: Xerais, 2010.

PEREIRA, Claudio; BACELAR, Jefferson. Política, instituições e personagens da Bahia (1850-1930). Salvador: Editora da Universidade Federal da Bahia, 2013.

PIÑEIRO, Ramón. A filosofía da saudade. Vigo: Galaxia, 1984.

ROIG-RECHOU, Blanca-Ana (coord). Historia da Literatura Infantil e Xuvenil Galega. Vigo: Xerais, 2015.

SILVA, Érica Sarmiento da. Galegos no Rio de Janeiro (1850-1970). Tese de Doutorado em História apresentada à Faculdade de História da Universidade de Santiago de Compostela. Santiago de Compostela, 2006.

VILLARES, Ramón. História da Galiza: uma memória dos avôs europeus. Vigo: Mar Maior; Galaxia, 2015.

Nota do editor:

Artigo submetido para avaliação em: 18 de fevereiro de 2021.

Aprovado em sistema duplo cego em: 13 de maio de 2021. 